\title{
Hemostatic effect of tourniquet combined with tranexamic acid in total knee arthroplasty: a network meta-analysis
}

\author{
Yimin Zhang ${ }^{1 \dagger}$, Bao Lang $^{2 \dagger}$, Guifeng Zhao ${ }^{3^{*}}$ and Fengming Wang ${ }^{4^{*}}$
}

\begin{abstract}
Background: There are various techniques to reduce blood loss in total knee arthroplasty (TKA), including the use of a tourniquet and tranexamic acid (TXA). In this study, we studied the combined effect of TXA with a tourniquet on blood loss in the setting of primary TKA.

Methods: Randomized controlled trials (RCTs) of nine treatment methods were included (placebo, intravenous [i.v.] TXA, topical TXA, i.v-combined topical TXA, oral TXA, placebo + tourniquet, i.V. TXA +tourniquet, topical TXA + tourniquet, and i.v.-combined topical TXA + tourniquet). The patients were divided into eight groups according to the different treatment strategies, with 30 cases per group. The differences in the total blood volume, the number of patients transfused, the hemoglobin before and after the operation, and complications after the operation were compared.

Results: Totally 15 RCTs meeting our inclusion criteria were collected in this study. Compared with the placebo + tourniquet group, the i.v. TXA + tourniquet group displayed lower hemoglobin reduction value, pulmonary embolism (PE) incidence, total blood loss, and blood transfusion risk; the topical TXA + tourniquet group showed reduced PE incidence, total blood loss, and blood transfusion risk, and the i.v.-combined topical TXA and i.v.-combined topical TXA + tourniquet groups showed decreased total blood loss and lower blood transfusion risk. Retrospective clinical study results also demonstrated that the efficacy of i.v.-combined topical TXA was the best.
\end{abstract}

Conclusions: Our meta-analysis indicates that i.v--combined topical TXA provides a low total blood loss without increasing the blood transfusion risk in patients undergoing total knee replacement surgery.

Keywords: Total knee replacement, Tourniquets, Tranexamic acid, Hemostasis, Randomized controlled trial

\footnotetext{
*Correspondence: zhaoguifeng69@126.com; wangfengming0331@163.com

${ }^{+}$Yimin Zhang and Bao Lang are co-first authors

${ }^{3}$ Medical Department, Weifang People's Hospital, No. 151, Guangwen Road,

Kuiwen District, Weifang 261000, Shandong Province, People's Republic of

China

${ }^{4}$ Orthopaedics Department, People's Hospital of Xiashan Ecological and

Economic Development Zone, No. 1, Xiashou Road, Xiashan District, Weifang

261325, Shandong Province, People's Republic of China

Full list of author information is available at the end of the article
}

(c) The Author(s). 2020 Open Access This article is licensed under a Creative Commons Attribution 4.0 International License, which permits use, sharing, adaptation, distribution and reproduction in any medium or format, as long as you give appropriate credit to the original author(s) and the source, provide a link to the Creative Commons licence, and indicate if changes were made. The images or other third party material in this article are included in the article's Creative Commons licence, unless indicated otherwise in a credit line to the material. If material is not included in the article's Creative Commons licence and your intended use is not permitted by statutory regulation or exceeds the permitted use, you will need to obtain permission directly from the copyright holder. To view a copy of this licence, visit http://creativecommons.org/licenses/by/4.0/ The Creative Commons Public Domain Dedication waiver (http://creativecommons.org/publicdomain/zero/1.0/) applies to the data made available in this article, unless otherwise stated in a credit line to the data. 


\section{Background}

Total knee arthroplasty (TKA) remains one of the most successful orthopedic operations to relieve pain and improve function in patients with arthritis [1]. The prevalence of TKA has increased dramatically due to the aging of the population and a rise in per capita utilization [2]. TKA leads to excessive perioperative blood loss, which can result in anemia and blood transfusions [3]. Indeed, allogenic transfusion is the standard method for managing acute blood loss following TKA [4]. However, the use of allogeneic transfusion can lead to undesirable adverse events such as infection, immunologic reaction, and even myocardial infarction [5]. Many blood preservation strategies have been proposed to reduce the operation-related blood loss and minimize the risk of postoperative blood transfusion, such as the use of the antifibrinolytic medication tranexamic acid (TXA) and application of a tourniquet [6, 7].

The application of tourniquet in TKA can improve the operative field of vision, reduce intraoperative blood loss, and improve the quality of cementation by providing a relatively bloodless operation site [8]. Nonetheless, the clinical role of the tourniquet in TKA remains a controversial matter. Ajnin et al. have proposed that TKA without tourniquet could reduce post-operative pain, swelling, and occult blood loss, including blood oozing into adjacent soft tissues and knee joints, thus improving the range of activity and enabling the entry of patients in rehabilitation training, while reducing the length of hospital stay [9]. Indeed, tourniquet use after TKA can provoke various complications, including a higher rate of deep vein thrombosis (DVT), wound infections, and nerve damage [10]. A recent study has shown that tourniquet application can decrease muscle strength and reduce knee range of motion (ROM), thus interfering with functional recovery after TKA [11].

Other research shows that tranexamic acid (TXA) treatment in conjunction with a tourniquet could compensate for the disadvantages of tourniquet use [7]. TXA, as an antifibrinolytic agent, is a synthetic lysine derivative, which can reduce blood loss by reversibly competing for the binding site of lysine on plasminogen to fibrin [12]. Accumulating evidence has also confirmed the benefits of TXA in decreasing blood loss and the transfusion rate in TKA [13]. In recent decades, the efficacies of intravenous, oral, and topical use of TXA has been compared in numerous studies, without showing distinct benefits from one route of administration [14]. A meta-analysis study compared the efficacy of topical intra-articular administration TXA versus placebo in TKA, which showed similar efficacies in reducing blood loss, hemoglobin reduction and the requirement for blood transfusion, without increasing adverse reactions [15]. Moreover, Lin at al. have confirmed that i.v.-combined topical with TXA could decrease the total blood loss and subsequent need for transfusion without increasing the occurrence of DVT in comparison to the topical, intravenous TXA alone [16]. The literature is largely unclear regarding the best-practice use of the tourniquet and TXA in the context of TKA surgery. Consequently, we made a meta-analysis of the nine treatment methods, aiming to determine if the use of a tourniquet in conjunction with TXA would improve total blood loss, transfusion rate, and complication rates.

\section{Material and methods \\ Data sources}

Relevant references were retrieved manually using the PubMed, EMBASE, Cochrane Library, and other English databases. The search range extended from the establishment to December 2019, with the use of combinations of keywords, i.e., total knee replacement, tourniquet, tranexamic acid, total knee arthroplasty, and randomized controlled trial (RCT).

\section{Inclusion and exclusion criteria}

Inclusion criteria: (1) study type: randomized controlled study; (2) intervention measures: placebo, intravenous (i.v.) TXA, topical TXA, i.v.-combined topical TXA, oral TXA, placebo + tourniquet, i.v. TXA + tourniquet, and topical TXA + tourniquets; (3) study subjects: patients (over 45 years old) who suffered from osteoarthritis or rheumatoid arthritis have undergone TKA for the first time; (4) results, including blood loss or transfusion risk. Exclusion criteria: (1) patients had previously received knee surgery; (2) patients who received bilateral knee arthroplasty; (3) patients with a history of deep vein thrombosis (DVT) and pulmonary embolism (PE); (4) patients with osteoporosis; (5) patients with severe anemia $(\mathrm{Hb}<60 \mathrm{~g} / \mathrm{L})$, coagulation dysfunction and peripheral vascular diseases; (6) non-randomized controlled study design; (7) republished literature, (8) conference reports, systematic reviews or abstract article; and (9) non-English literature.

\section{Data extraction and quality evaluation}

Using a unified data collection table, two researchers independently extract the data included in the literature search. If a dispute emerged in the data extraction process, the dispute would be solved by multiple researchers. Randomized controlled trials were evaluated by more than two researchers according to the Cochrane risk bias assessment tool [17]. The tool included six fields: random assignment, assignment concealment, blinding, loss of outcome data, selection of outcome reports, and other biases. The assessment included assigning a judgment of "yes," "no," or "unclear" for each domain to designate a low, high, or unclear risk of bias, respectively. If one or no domains were deemed "unclear" or "no", the study was classified as having a 
low risk of bias. If two or three domains were deemed "unclear" or "no," the study was classified as having a moderate risk of bias, whereas the study was classified as having a high bias risk if four or more domains were deemed "unclear" or "no" [18]. Quality assessment and investigation of publication bias were carried out using Review Manager 5 (RevMan 5.2.3, Cochrane Collaboration, Oxford, UK).

\section{Follow-up retrospective cohort study protocol Patient data}

The retrospective case-control study was carried out in the People's Hospital of Xiashan Ecological and Economic Development Zone. The data of TKA patients collected prospectively from December 2015 to December 2019 were reviewed. According to different surgical treatment measures, patients were divided into eight groups (i.v. TXA, topical TXA, i.v.-combined topical TXA, oral TXA, Placebo + tourniquet, i.v. TXA + tourniquets, Topical TXA + tourniquet, and i.v.-combined topical TXA + tourniquet). For each group, 32 cases (61 males and 95 females; ranging in age from 45 to 75 years with a mean age of $66.01 \pm 4.98$ ) years) meeting the inclusion criteria were randomly selected for follow-up analysis to compare their total blood loss, risk of blood transfusion, changed hemoglobin values, and postoperative complications.

Inclusion criteria in the retrospective study: (1) patients were over 45 years old when undergoing surgery; (2) patients had osteoarthritis; (3) patients received TKA for the first time; (4) and patients were treated with TXA or tourniquet. Exclusion criteria: (1) patients had previously received knee surgery; (2) patients with a history of DVT and PE; (3) patients with osteoporosis; (4) patients with severe anemia, coagulation dysfunction, and peripheral vascular diseases $(\mathrm{Hb}<60 \mathrm{~g} / \mathrm{L})$. This study was approved by the internal review committee for orthopaedic research as an observational human study. All study data and information collected from patient files are confidential and are subject to the Declaration of Helsinki.

\section{Operative method}

All operations were performed by the same orthopedic operation group under similar anesthesia and operation protocols. No drainage tube was placed during the operation. In the first group, patients received an i.v. injection of $1.0 \mathrm{~g}$ TXA $10 \mathrm{~min}$ before incision and without tourniquet during the operation (i.v. TXA group). In the second group, after the closure of the joint capsule, patients were injected into the joint with $1 \mathrm{~g} / 20 \mathrm{~mL}$ normal saline TXA once without tourniquet during the operation (Topical TXA group). In the third group, patients were intravenously injected with $1.0 \mathrm{~g}$ TXA at $10 \mathrm{~min}$ before surgical incision and $1 \mathrm{~g} / 20 \mathrm{~mL}$ normal saline TXA was injected into the joint after closure of the joint capsule, and without tourniquet during the operation (i.v.-combined topical TXA group). In the fourth group, $2 \mathrm{~g}$ (4 tablets, $500 \mathrm{mg}$ each) TXA was administered orally $2 \mathrm{~h}$ before the operation, and $1 \mathrm{~g}$ was repeated $6 \mathrm{~h}$ and $12 \mathrm{~h}$ after the operation, respectively, without tourniquet during the operation (Oral TXA group). In the fifth group, patients were intravenously injected with $10 \mathrm{mg} / \mathrm{kg}$ placebo before and $3 \mathrm{~h}$ after the release of the tourniquet, without treatment with TXA. Tourniquet was used throughout the operation. The tourniquet was released after the incision was sutured and pressure bandaged (placebo + tourniquet group). In the sixth group, patients were intravenously injected with $1.0 \mathrm{~g}$ TXA $10 \mathrm{~min}$ before incision, in conjunction with the tourniquet used throughout the operation. The tourniquet was released after the incision was sutured and pressure bandaged (i.v. TXA + tourniquets group). In the seventh group, after the closure of the joint capsule, patients were injected with $1 \mathrm{~g} / 20 \mathrm{~mL}$ normal saline TXA once in the joint with tourniquet used throughout the operation. The tourniquet was released after the incision was sutured and pressure bandaged (Topical TXA + tourniquet group). In the eighth group, patients were intravenously injected with $1.0 \mathrm{~g}$ TXA was $10 \mathrm{~min}$ before incision and $1 \mathrm{~g} / 20 \mathrm{~mL}$ normal saline TXA was injected into the joint after closure of the joint capsule with tourniquet used throughout the operation. The tourniquet was released after the incision was sutured and pressure bandaged (i.v.-combined topical TXA + tourniquet group).

\section{Outcome measure}

Total blood loss, the number of patients transfused, and hemoglobin (HB) 24 hs before and after operation were the main results, while DVT, PE, and operation time were the secondary results.

\section{Statistical analysis}

Revman 5 software (version 5.3, Cochrane Collaboration, Oxford, UK) was used for evaluation and statistical analysis. The continuous data were calculated by weighted mean difference (WMDs) and 95\% confidence interval (CI), while the binary classification data were calculated by risk ratio (OR) and $95 \%$ confidence interval (CI). Chisquare test and $I^{2}$ test were used to test heterogeneity. If $x^{2}>0.1$ or $I^{2}<50 \%$, then a fixed consequence model was used, and otherwise, a random effect model was used. The R 3.2.1 software was used to draw a network diagram.

The node-splitting method was used to evaluate the consistency between direct and indirect evidence, and the consistency or inconsistency model was selected based on the results. If the result of node segmentation showed $p>0.05$, the consistency model was selected 
[19]. To assist in the interpretation of OR/WMDs, we calculated the probability of each intervention being the most effective treatment method following a Bayesian approach using probability values summarized as the surface under the cumulative ranking curve (SUCRA) [20, 21]. All computations were done using R (V.3.2.1) package gemtc (V.0.6), along with the Markov Chain Monte Carlo engine Open BUGS (V.3.4.0). All experimental data were processed and analyzed using the Statistic Package for Social Science (SPSS) 21.0 statistical software (IBM Corp. Armonk, NY, USA). Measurement data are presented as mean \pm standard deviation. Comparisons among multiple groups were analyzed using one-way analysis of variance (ANOVA), followed by Tukey's post hoc test. Enumeration data were analyzed by a chi-squared test. A value of $p<0.05$ was considered to be statistically significant.

\section{Results}

The baseline characteristics of the included studies

In this study, there were 1498 related literature, 148 repetitive literature, 215 letters or reviews, and 108 nonhuman research literature. A total of 142 non-English literature were excluded. After the evaluation of the remaining 885 literature, 446 non-randomized controlled studies, 408 non-TKA literature, and 16 incomplete literature were excluded. Finally, 14 randomized controlled studies met the inclusion criteria used for this meta-analysis [5, 8, 22-34] (Fig. S1). A total of 1338 patients with osteoarthritis or rheumatoid arthritis and other diseases who had undergone corresponding operations, among whom the largest group had received i.v. injection of TXA drugs combined with a tourniquet (Fig. 1). The study was published from 1996 to 2018. Among them, 8 studies were from the European and American population, 6 from the Asian population, and 4 out of 14 studies were three armed studies and 10 were two armed studies. The baseline characteristics of the included literature are shown in Table 1, the Cochrane system bias evaluation is shown in Fig. 2, and the funnel plot is shown in Fig. 3.th=tlb=

\section{Meta-analysis results}

As shown in Table 2, in order to compare the hemostasis effect of 9 treatment measures on TKA, we made a direct matching comparison and found that in terms of blood loss, compared with the placebo group, the total blood loss of i.v. TXA group and topical TXA group was relatively less $(\mathrm{WMD}=-277.34,95 \% \mathrm{CI}=$ -431.85 to $-122.83, \mathrm{WMD}=-307.78,95 \% \mathrm{CI}=-460.92$ to -154.64 , respectively). Compared with the i.v. TXA

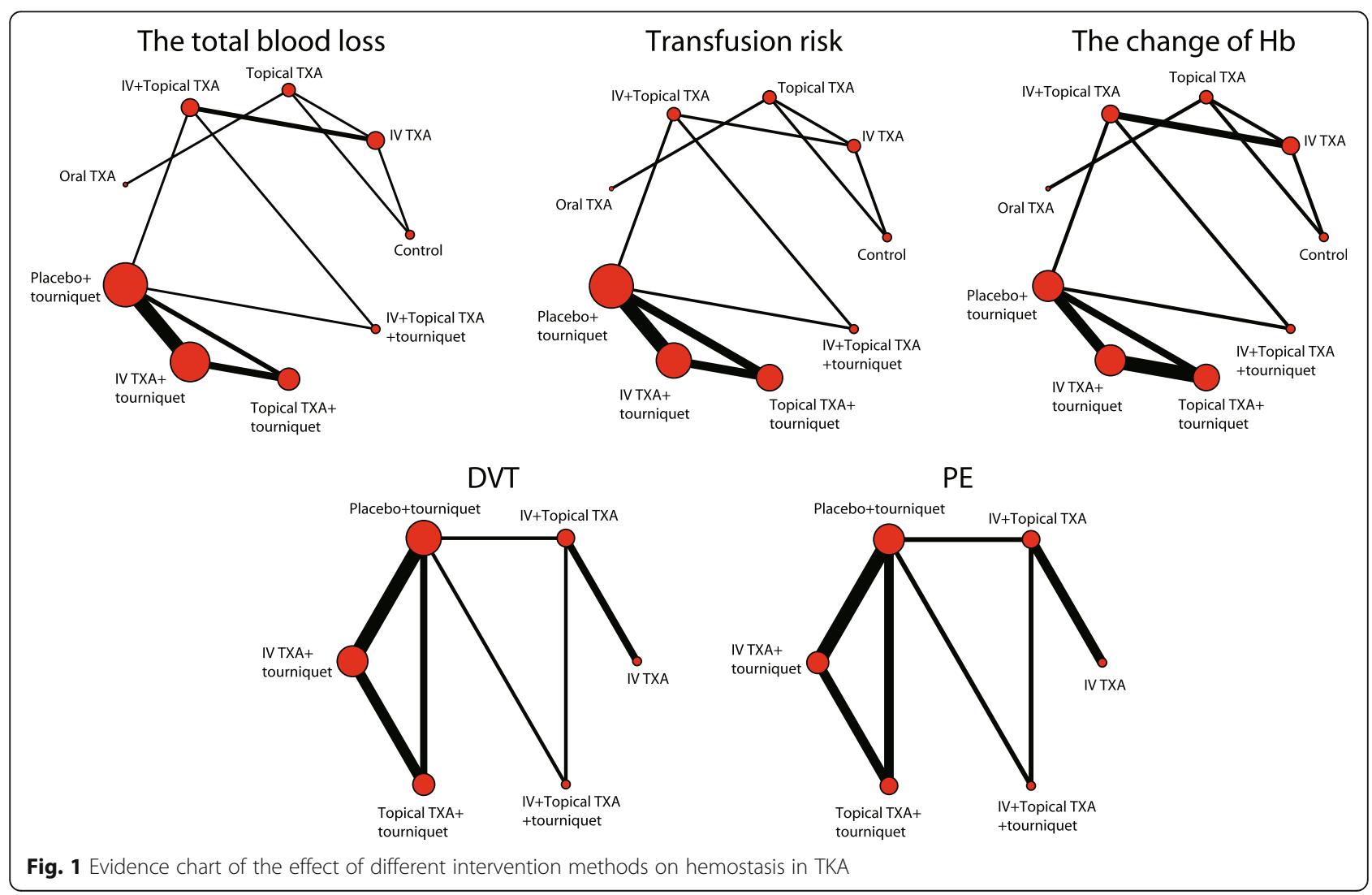




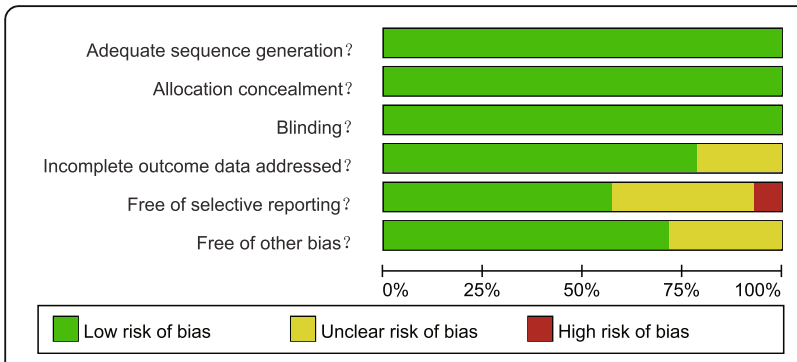

Fig. 2 Cochrane system bias evaluation of included literature

group, the total blood loss of i.v.-combined topical TXA group reduced (WMD $=-218.13,95 \% \mathrm{CI}=-282.59$ 153.68). Compared with i.v.-combined topical group, there was higher total blood loss in the placebo + tourniquet group and i.v.-combined topical TXA + tourniquet group $(\mathrm{WMD}=956.60,95 \% \mathrm{CI}=829.31-1083.89$, (WMD $=106.80,95 \% \mathrm{CI}=13.04-200.56$, respectively). Compared with the placebo + tourniquet group, the total blood loss in the i.v. TXA + tourniquet group, the topical TXA + tourniquet group and the i.v.-combined topical TXA + tourniquet group was relatively less $(\mathrm{WMD}=-156.09,95 \% \mathrm{CI}=-179.41$ to -132.78 , WMD $=-79.20,95 \% \mathrm{CI}=-106.34$ to $-52.05, \mathrm{WMD}=-849.80$, $95 \% \mathrm{CI}=-987.51$ to -712.09 , respectively). In terms of blood transfusion risk, compared with the placebo group, the i.v. TXA group and the topical TXA group had a relatively low blood transfusion risk (or $=0.23$, $95 \% \mathrm{CI}=0.08-0.74$, or $=0.35,95 \% \mathrm{CI}=0.13-1$, perspective). Compared with the placebo + tourniquet group, the i.v. TXA + tourniquet group, the topical TXA + tourniquet group, and the i.v.-combined topical TXA + tourniquet group had a relatively low blood transfusion risk $(\mathrm{OR}=0.09,95 \% \mathrm{CI}=0.04-0.17, \mathrm{OR}=0.19$, $95 \% \mathrm{CI}=0.10-0.37, \mathrm{OR}=0.05,95 \% \mathrm{CI}=0.00-0.88$, respectively). In terms of the change value of hemoglobin, compared with the placebo group, the reduction value of hemoglobin in the i.v.-combined topical TXA group was relatively low $(\mathrm{WMD}=1.17,95 \% \mathrm{CI}=0.54-1.80$, WMD $=1.42,95 \% \mathrm{CI}=0.78-2.06$, respectively), compared with the i.v.-combined topical TXA group, the reduction value of hemoglobin in the i.v.-combined topical TXA group was relatively low (WMD $=0.67,95 \% \mathrm{CI}=0.48-$ 0.86). Compared with the i.v.-combined topical TXA group, there was more reduction of the hemoglobin value in the placebo + tourniquet group and the i.v.combined topical TXA + tourniquet group (WMD = $-1.61,95 \% \mathrm{CI}=-1.90$ to $-1.32, \mathrm{WMD}=-0.20,95 \% \mathrm{CI}=$ -0.38 to -0.02 , respectively). Compared with the placebo + tourniquet group, there was less reduction in the hemoglobin value in the i.v. TXA + tourniquet group, topical TXA + tourniquet group, and the i.v.-combined

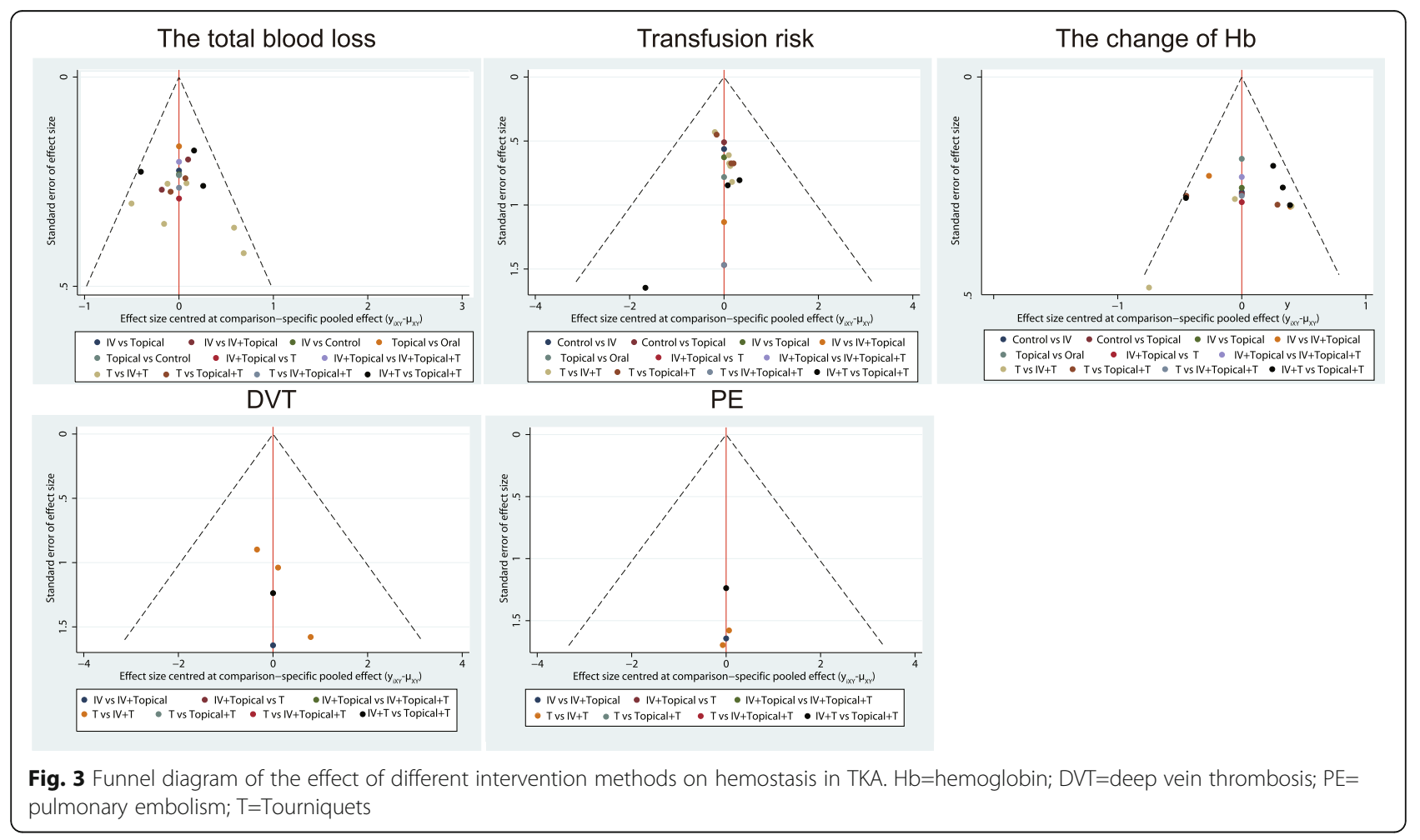




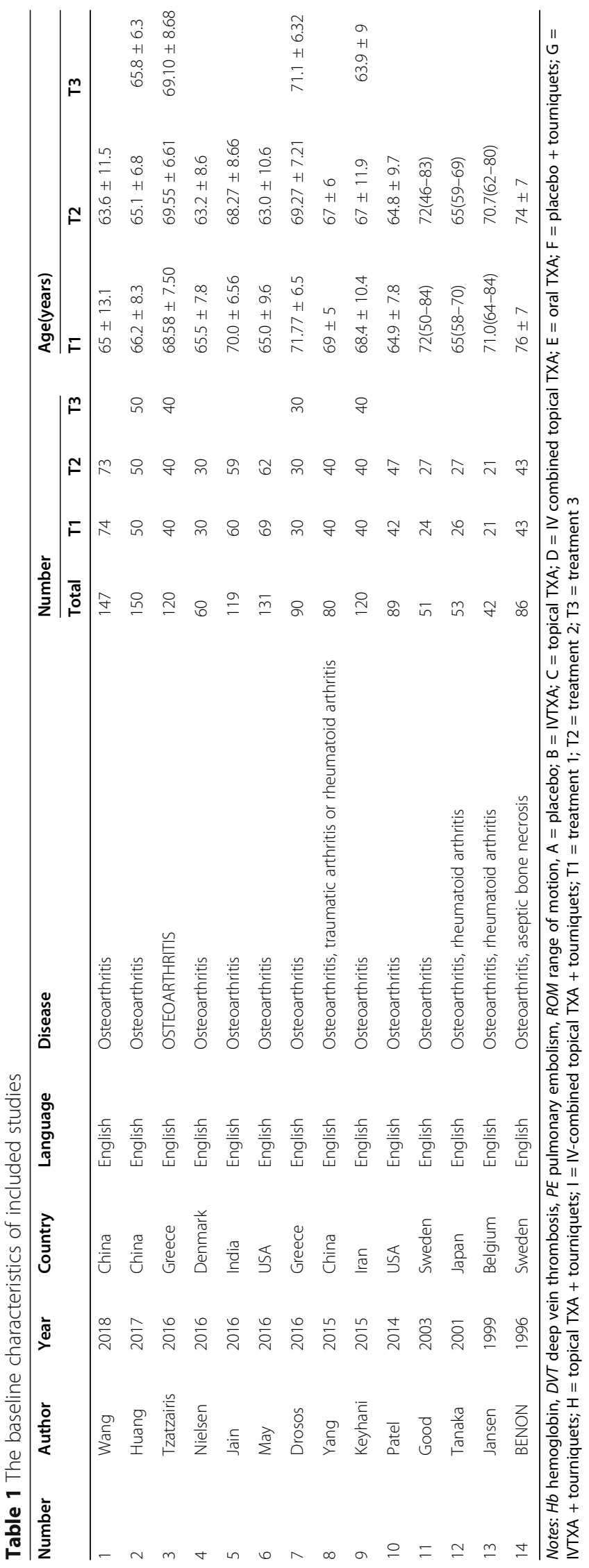




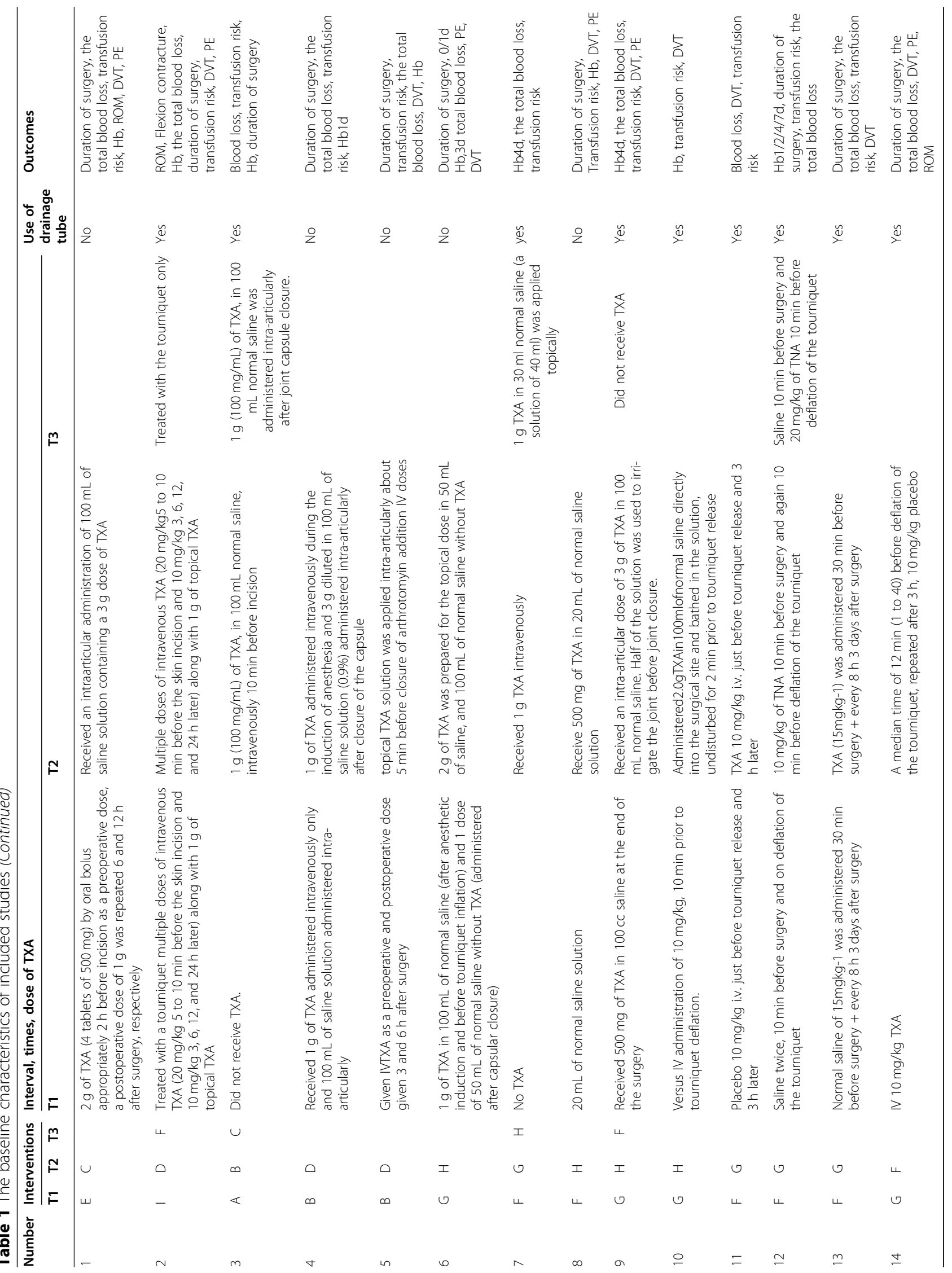


Table 2 Estimated OR/WMD and 95\% Cl from pairwise meta-analysis in terms of Blood loss, Transfusion risk, Change of Hb, DVT and PE

\begin{tabular}{|c|c|c|c|c|}
\hline \multirow[t]{2}{*}{ Included studies } & \multirow[t]{2}{*}{ Comparisons } & \multicolumn{3}{|l|}{ Pairwise meta-analysis } \\
\hline & & $\overline{W M D(95 \% C l)}$ & $I^{2}$ & $P_{h}$ \\
\hline \multicolumn{5}{|c|}{$\begin{array}{l}\text { The total blood loss } \\
\text { (PMID:29544472;PMID:29257010;PMID:27267228;PMID:27194493;PMID:26507526;PMID:27259391;PMID:27222617;PMID:26894222;PMID:12697586;PMID } \\
\text { 11476309;PMID:10673876; PMID:8636182) }\end{array}$} \\
\hline 1 study & IV vs. control & $-277.34(-431.85-122.83)$ & NA & NA \\
\hline 1 study & Topical vs. control & $-307.78(-460.92-154.64)$ & NA & NA \\
\hline 1 study & Topical vs. IV & $-30.44(-163.81-102.93)$ & NA & NA \\
\hline 2 studies & IV + topical vs. IV & $-218.13(-282.59-153.68)$ & $46.8 \%$ & 0.17 \\
\hline 1 study & Oral vs. topical & $-83.60(-203.84-36.64)$ & NA & NA \\
\hline 1 study & T VS. IV + topical & $956.60(829.31-1083.89)$ & NA & NA \\
\hline 6 studies & $\mathrm{IV}+\mathrm{T}$ vs. $T$ & $-156.09(-179.41-132.78)$ & $98.1 \%$ & $<0.01$ \\
\hline 2 studies & Topical+T vs. T & $-79.20(-106.34-52.05)$ & $87.6 \%$ & $<0.01$ \\
\hline 3 studies & Topical+T vs. IV + T & $10.90(-7.95-29.72)$ & $62.5 \%$ & 0.07 \\
\hline 1 study & IV + topical+T vs. IV + topical & $106.80(13.04-200.56)$ & NA & NA \\
\hline 1 study & IV + topical+T vs. T & $-849.80(-987.51-712.09)$ & NA & NA \\
\hline
\end{tabular}

Transfusion risk

(PMID:29544472;PMID:29257010;PMID:27267228;PMID:26507526;PMID:27222617;PMID:24816760;PMID:26894222;PMID:24768543;PMID:12697586;PMID: 11476309;PMID:10673876)

$\begin{array}{ll}1 \text { study } & \text { IV vs. control } \\ 1 \text { study } & \text { Topical vs. control } \\ 1 \text { study } & \text { Topical vs. IV } \\ 1 \text { study } & \text { IV + topical vs. IV } \\ 1 \text { study } & \text { Oral vs. topical } \\ 1 \text { study } & \text { T VS. IV + topical } \\ 5 \text { studies } & \text { IV + T vs. T } \\ 3 \text { studies } & \text { Topical+T vs. T } \\ 3 \text { studies } & \text { Topical+T vs. IV + T } \\ 1 \text { study } & \text { IV + Topical+T vs. T }\end{array}$

$\mathbf{0 . 2 3}(\mathbf{0 . 0 8 - 0 . 7 4 )}$
$\mathbf{0 . 3 5}(\mathbf{0 . 1 3}-\mathbf{1 . 0 0})$
$1.48(0.43-5.14)$
$0.24(0.03-2.23)$
$0.73(0.16-3.38)$
$20.20(1.13-360.28)$
$\mathbf{0 . 0 9}(\mathbf{0 . 0 4}-\mathbf{0 . 1 7})$
$\mathbf{0 . 1 9}(\mathbf{0 . 1 0 - 0 . 3 7 )}$
$0.99(0.34-2.85)$

The change of $\mathrm{Hb}$ (PMID:29544472;PMID:29257010;PMID:27267228;PMID:27194493;PMID:26507526;PMID:27259391;PMID:27222617;PMID:26894222;PMID:24768543;PMID: 11476309)

$\begin{array}{ll}1 \text { study } & \text { IV vs. control } \\ 1 \text { study } & \text { Topical vs. control } \\ 1 \text { study } & \text { Topical vs. IV } \\ 2 \text { studies } & \text { IV + topical vs. IV } \\ 1 \text { study } & \text { Oral vs. topical } \\ 1 \text { study } & \text { T VS. IV + topical } \\ 3 \text { studies } & \text { IV + T vs. T } \\ 2 \text { studies } & \text { Topical+T vs. T } \\ 4 \text { studies } & \text { Topical+T vs. IV + T } \\ 1 \text { study } & \text { IV + topical+T vs. IV + topical } \\ 1 \text { study } & \text { IV + topical+T vs. T }\end{array}$

$\begin{array}{lll}\mathbf{1 . 1 7}(\mathbf{0 . 5 4 - 1 . 8 0 )} & \text { NA } & \text { NA } \\ \mathbf{1 . 4 2}(\mathbf{0 . 7 8 - 2 . 0 6 )} & \text { NA } & \text { NA } \\ 0.25(-0.32-0.82) & \text { NA } & \text { NA } \\ \mathbf{0 . 6 7}(\mathbf{0 . 4 8 - 0 . 8 6 )} & 0 \% & 0.81 \\ 0.20(-0.13-0.53) & \text { NA } & \text { NA } \\ \mathbf{- 1 . 6 1 ( - 1 . 9 0 - 1 . 3 2 )} & \text { NA } & \text { NA } \\ \mathbf{2 . 5 0 ( 2 . 0 9 - 2 . 9 0 )} & 94.8 \% & <0.01 \\ \mathbf{1 . 4 2}(\mathbf{0 . 8 4 - 2 . 0 0 )} & 5.4 \% & 0.30 \\ \mathbf{0 . 5 7}(\mathbf{0 . 3 1}-\mathbf{0 . 8 4}) & 92.0 \% & <0.01 \\ \mathbf{- 0 . 2 0 ( - 0 . 3 8 - 0 . 0 2 )} & \text { NA } & \text { NA } \\ \mathbf{1 . 4 1}(\mathbf{1 . 1 1 - 1 . 7 1 )} & \text { NA } & \text { NA }\end{array}$

DVT

(PMID:29257010;PMID:27194493;PMID:26507526;PMID:27259391;PMID:24816760;PMID:26894222;PMID:24768543;PMID:12697586;PMID:10673876; PMID: 8636182)

1 study

IV + topical vs. IV

$0.33(0.01-8.35)$

NA

NA 
Table 2 Estimated OR/WMD and 95\% Cl from pairwise meta-analysis in terms of Blood loss, Transfusion risk, Change of Hb, DVT and PE (Continued)

\begin{tabular}{lllll}
\hline Included studies & Comparisons & Pairwise meta-analysis & $\boldsymbol{P}^{\mathbf{2}}$ & \multicolumn{1}{l}{} \\
\cline { 3 - 5 } & & WMD(95\%Cl) & $0 \%$ & 0.50 \\
\hline 3 studies & IV + T vs.T & $0.80(0.24-2.63)$ & NA & NA
\end{tabular}

PE

(PMID:29257010;PMID:27194493;PMID:26507526;PMID:27259391;PMID:24816760;PMID:26894222;PMID:10673876;PMID:8636182)

\begin{tabular}{|c|c|c|c|c|}
\hline 1 study & IV + topical vs. IV & $0.33(0.01-8.35)$ & NA & NA \\
\hline 2 studies & IV + T vs. T & $0.22(0.24-2.14)$ & $0 \%$ & 0.83 \\
\hline 1 study & Topical+T vs. IV + T & $0.55(0.05-6.21)$ & NA & NA \\
\hline
\end{tabular}

Notes: $W M D$ weighted mean difference, $95 \% \mathrm{Cl} 95 \%$ confidence intervals, $\mathrm{Hb}$ hemoglobin, $D V T$ deep vein thrombosis, $P E$ pulmonary embolism, Control = placebo; IV=IV TXA; topical = topical TXA; IV + topical = IV-combined topical TXA; Oral = oral TXA; T = placebo+tourniquets; IV $+\mathrm{T}=\mathrm{IV}$ TXA + tourniquets; Topical+T = topical TXA + tourniquets; IV + topical+T = IV-combined topical TXA + tourniquets

topical TXA + tourniquet group $(\mathrm{WMD}=1.41,95 \% \mathrm{CI}=$ 1.11-1.71, respectively). Compared with the i.v. TXA + tourniquet group, the hemoglobin reduction in the topical TXA + tourniquet group was relatively low (WMD $=0.57,95 \% \mathrm{CI}=0.31-0.84)($ Table 2$)$.

The results of the five outcome indicators, including total blood loss, risk of blood transfusion, hemoglobin change, DVT, and PE were analyzed by the method of node segmentation. It was found that the direct evidence and indirect evidence of all outcome indicators were consistent, and the consistency model should be used (all $p>0.05$ ) (Fig. 4).

The results of the meta-analysis showed that in comparison to the placebo + tourniquet group, the total blood loss decreased in i.v.-combined topical TXA group, i.v. TXA + tourniquet group, topical TXA +

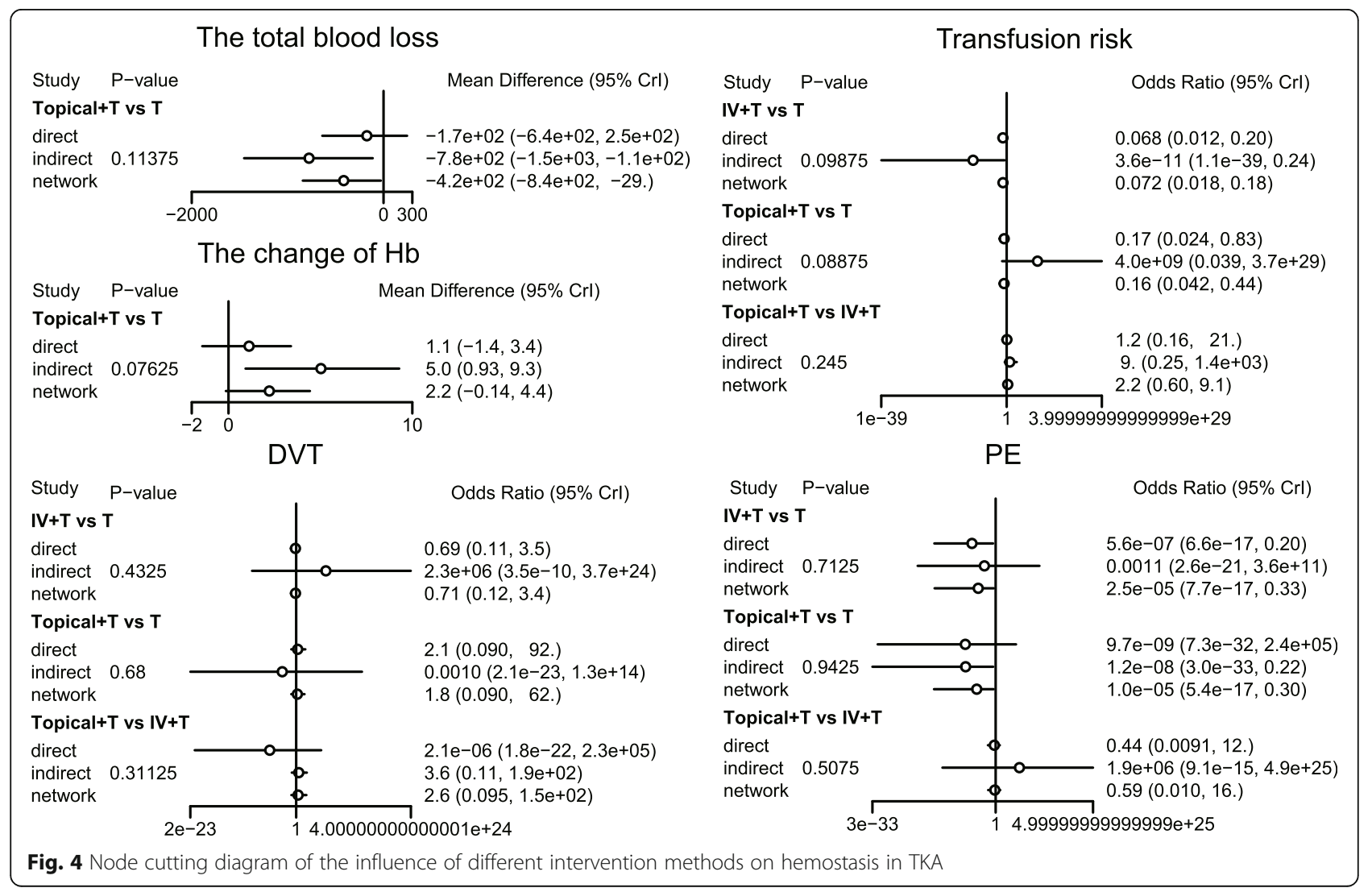


tourniquet group, combined i.v. plus topical TXA + tourniquet group. Thus, the hemostasis effect was relatively good in these four groups. Compared with the placebo + tourniquets group, the risk for blood transfusion was lower in the i.v. TXA + tourniquet group, the topical TXA + tourniquet group, and the i.v.-combined topical TXA + tourniquet group. Compared with i.v. TXA + tourniquet and topical TXA + tourniquet groups, blood transfusion risk was reduced in the i.v.-combined topical TXA + tourniquets group $(\mathrm{OR}=0.00,95 \% \mathrm{CI}=$ $0.00-0.31$; OR $=0.00,95 \% \mathrm{CI}=0.00-0.10$, respectively). Compared with the placebo + tourniquet group, the i.v. TXA + tourniquet group had a relatively low hemoglobin reduction $(\mathrm{WMD}=2.15,95 \% \mathrm{CI}=0.17-$ 4.06). Compared with the placebo + tourniquet group, the incidence of PE was lower in the i.v. TXA + tourniquet group and the topical TXA + tourniquet group $(\mathrm{OR}=0.00,95 \% \mathrm{CI}=0.00-0.21)$. However, in terms of DVT incidence, there was no significant difference in the effect of each intervention in TKA (Figs. 5, 6, 7, 8 and Table 3).

As shown in Table 4, the cumulative ranking probability SUCRA value of different interventions on hemostasis in TKA, in terms of total blood loss, blood transfusion risk, and hemoglobin change, the cumulative sorting probability of placebo + tourniquet group was higher than that of the other eight groups $(94.22 \%$, $100 \%, 80.26 \%$, respectively), suggesting that the hemostasis effect in the placebo + tourniquet group is relatively poor in TKA. The total blood loss (26.56\%) and the risk of blood transfusion $(24.33 \%)$ in the i.v.combined topical TXA group were lower than in the

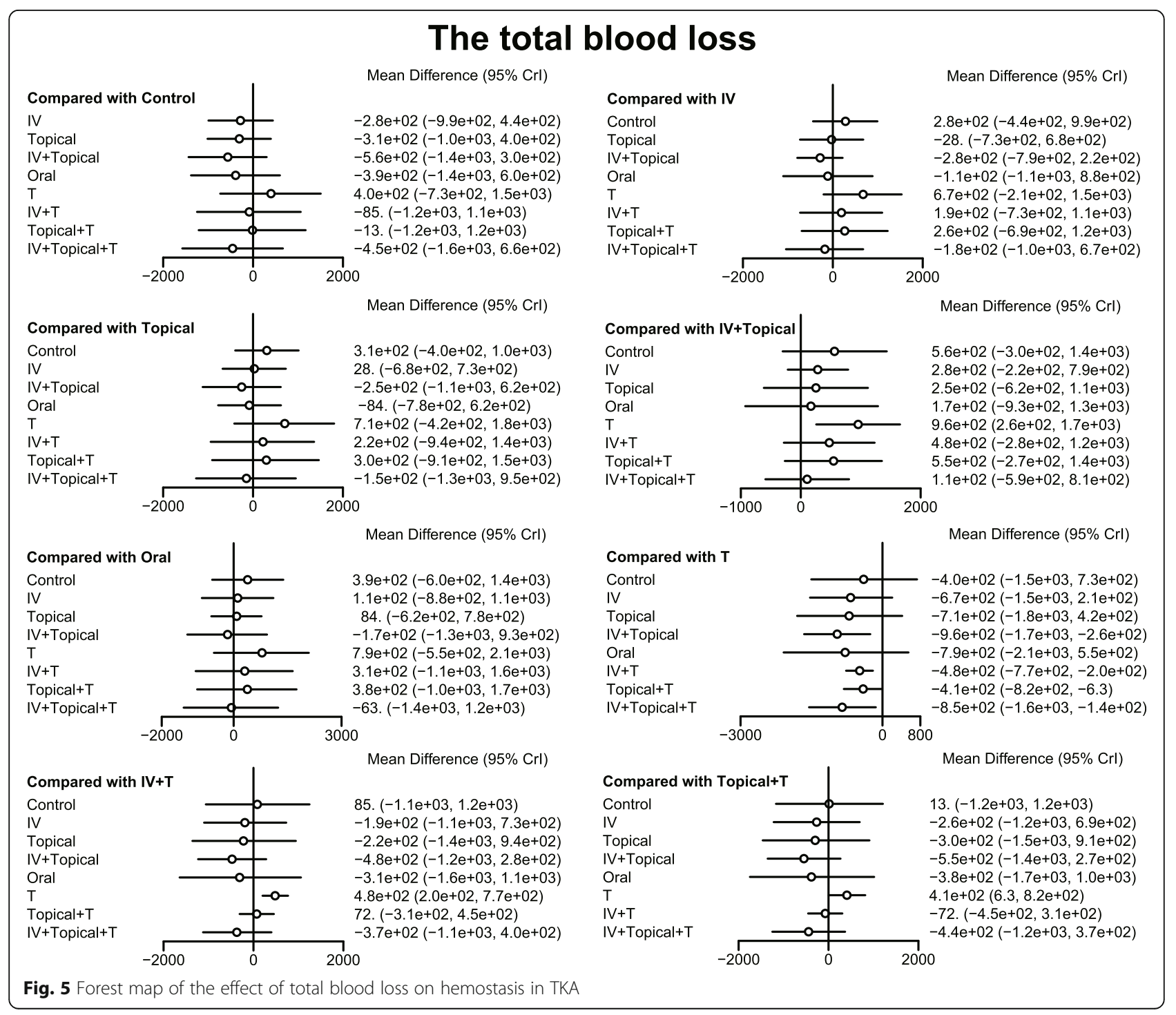




\section{Transfusion risk}
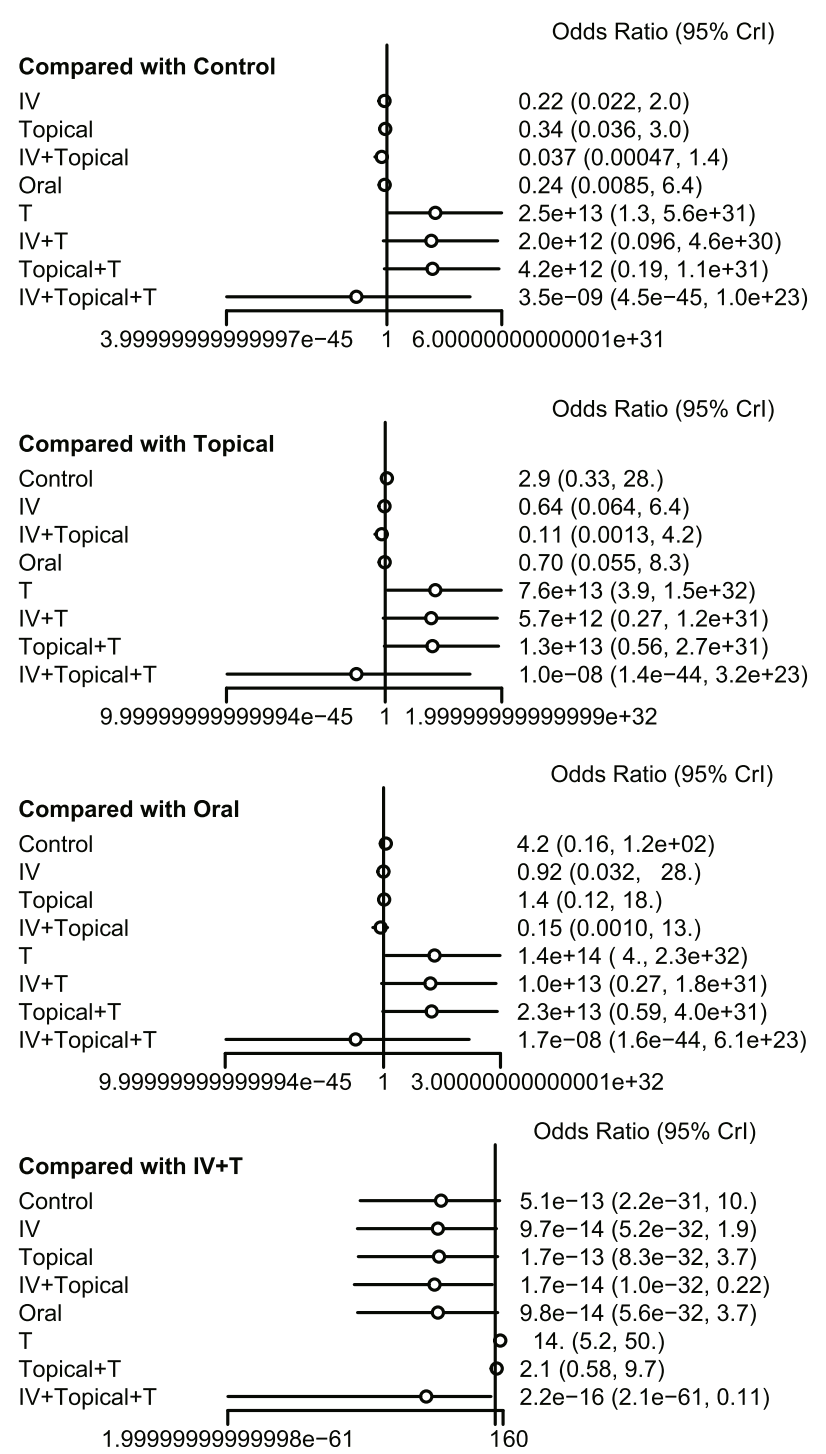

Fig. 6 Forest map of the effect of transfusion risk on hemostasis in TKA
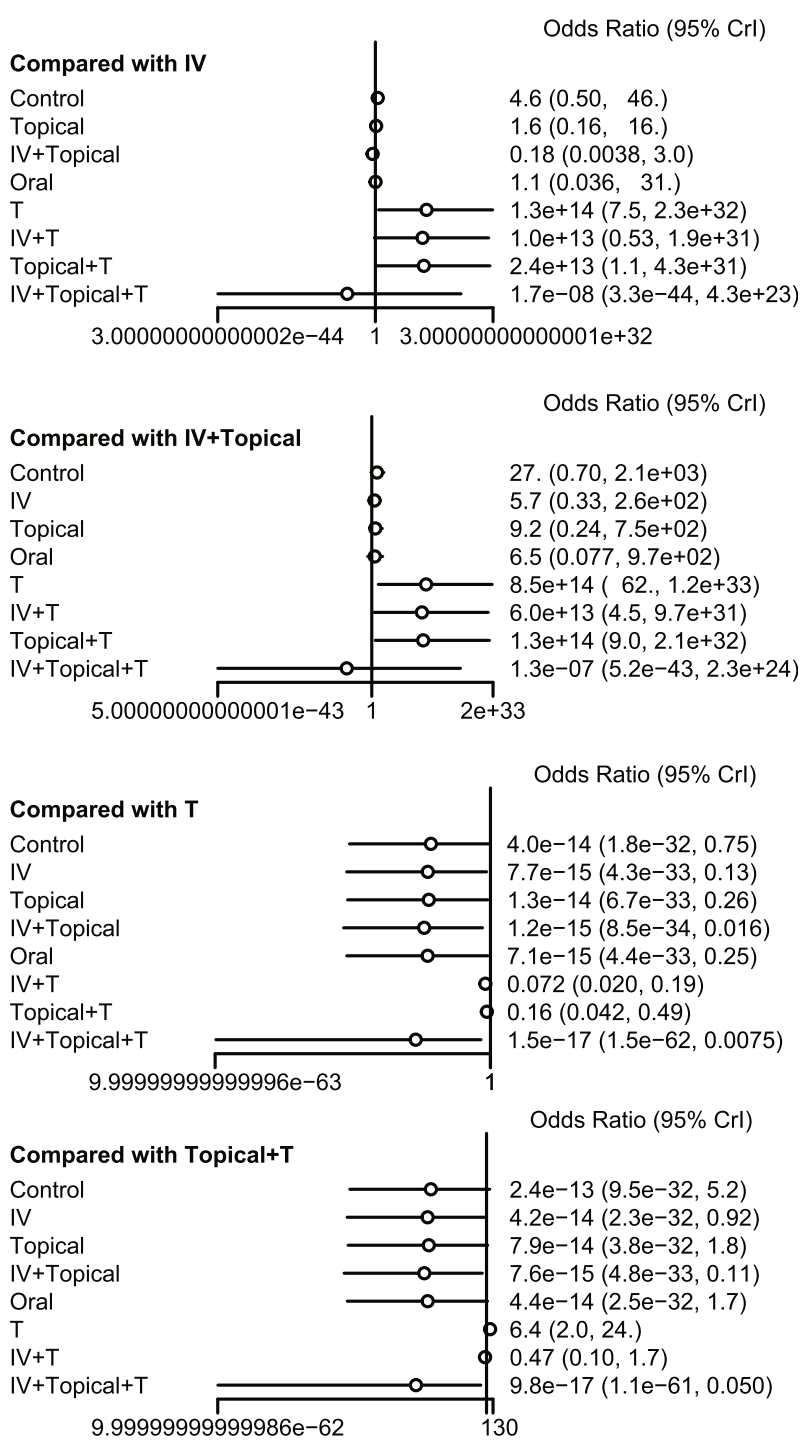

other eight groups, indicating a superior hemostasis effect. The cumulative sorting probability of hemoglobin reduction $(37.46 \%)$ in the topical TXA + tourniquets group was lower than that in the other eight groups

\section{Retrospective analysis of clinical research results}

As shown in Table 5, different treatment methods of TXA and tourniquet were significantly related to the total blood loss of TKA, the number of people who needed a blood transfusion, and the change of hemoglobin before and after the operation (all $p<0.05$ ), there was no significant correlation with gender, age, knee joint activity, operation time, and postoperative complications (all $p>0.05$ ). Among them, the indexes of i.v.-combined topical TXA group were better than the other seven groups.

\section{Discussion}

TKA is a complex surgery that often brings lifetransforming improvements in function, but perioperative complications still arise, notably in relation to excessive intra- and post-operative blood loss [12]. There is general acceptance that the application of tourniquet reduces intraoperative blood loss after TKA [8]. Moreover, various dosing regimens used for TXA have proven effective, including 


\section{The change of $\mathrm{Hb}$}
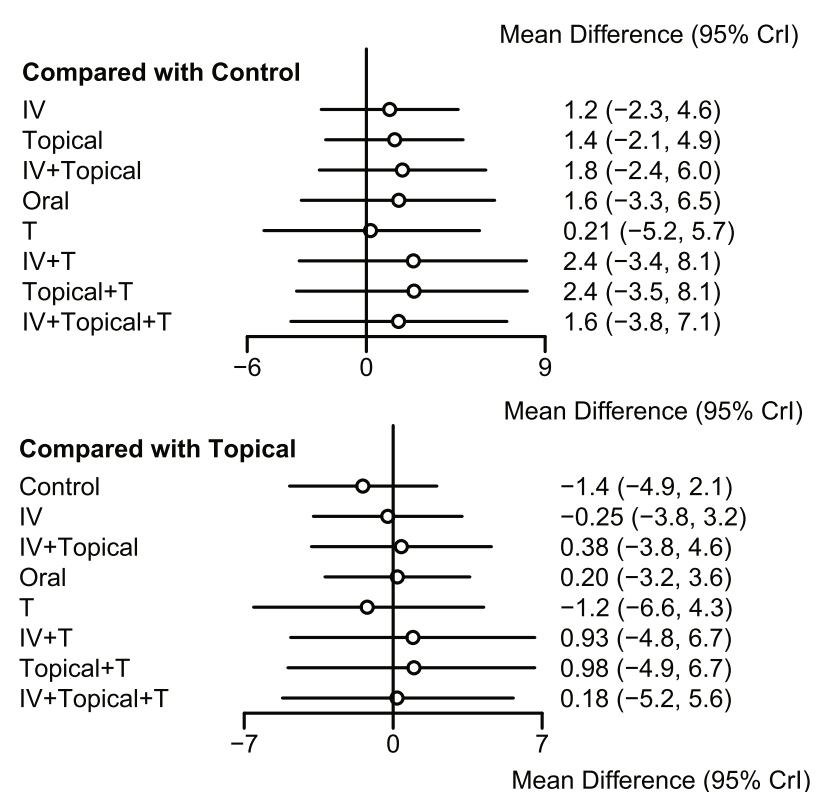

Compared with Oral Control

IV

Topical

IV+Topical

$T$

IV $+\mathrm{T}$

Topical $+\mathrm{T}$

IV+Topical+T

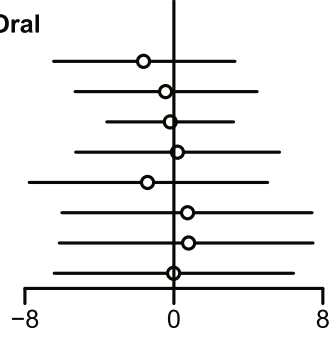

$-1.6(-6.5,3.3)$

$-0.45(-5.3,4.5)$

$-0.20(-3.6,3.2)$

$0.19(-5.3,5.7)$

$-1.4(-7.8,5.0)$

$0.73(-6.0,7.4)$

$0.79(-6.2,7.5)$

$-0.015(-6.4,6.4)$

Mean Difference (95\% Crl)

Compared with IV+T

Control

IV

Topical

IV+Topical

Oral

T

Topical+T

IV+Topical+T

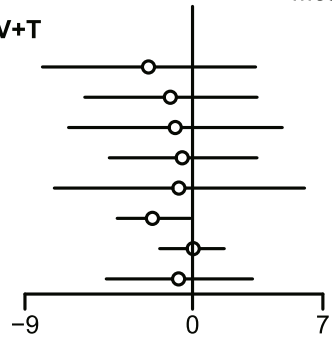

$-2.4(-8.1,3.4)$

$-1.2(-5.8,3.5)$

$-0.93(-6.7,4.8)$

$-0.55(-4.5,3.5)$

$-0.73(-7.4,6.0)$

$-2.2(-4.0,-0.12)$

$0.036(-1.8,1.7)$
$-0.75(-4.6,3.2)$

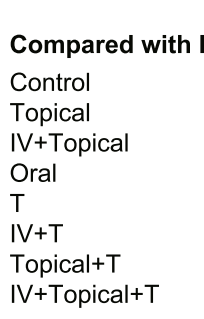

v

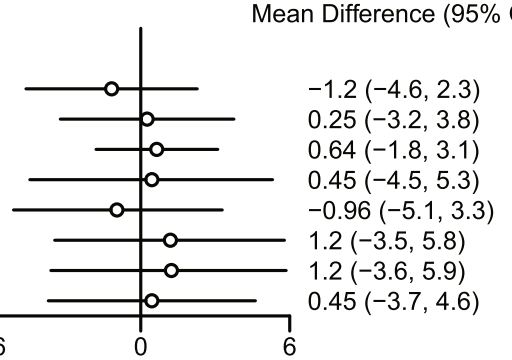

Mean Difference (95\% Crl)

Compared with IV+Topical

Control

IV

Topical

Oral

$\mathrm{T}$

IV+T

Topical+T

IV+Topical+T

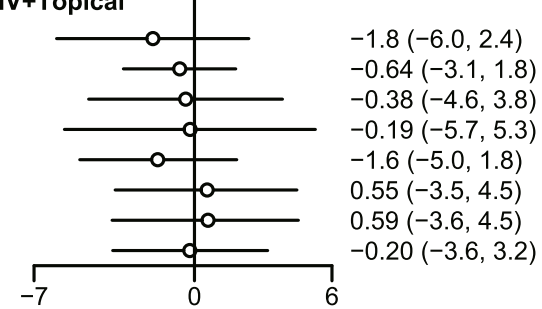

Mean Difference (95\% Crl)

Compared with T

Control

IV

Topical

IV+Topical

Oral

IV+T

Topical+T

IV+Topical+T

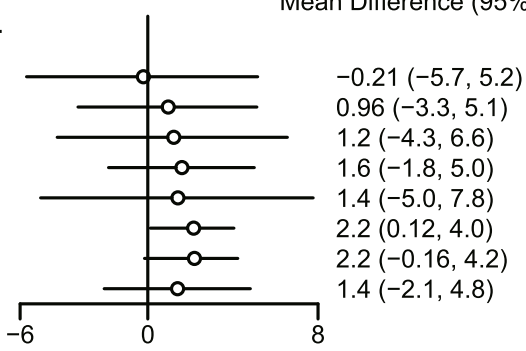

Mean Difference (95\% Crl)

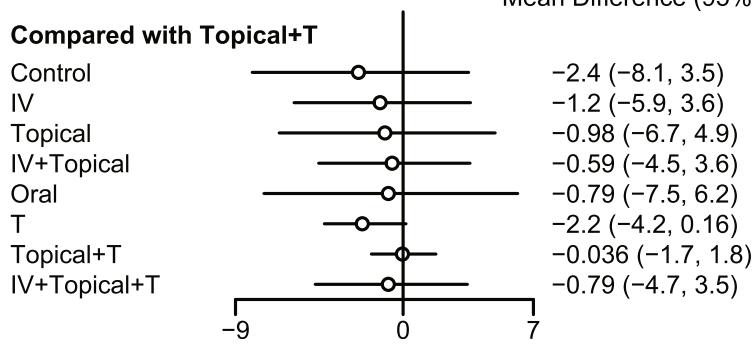

Fig. 7 Forest map of the effect of change value of hemoglobin on hemostasis in TKA

intra-articular (IA) and oral forms, likewise i.v. TXA alone or in conjunction with topical TXA. However, there is meager scientific evidence for the benefits of combining i.v. and topical TXA in the course of TKA [35]. Therefore, we conducted a network metaanalysis to assess hemostatic effects of nine variant treatment methods following TKA in this study. Based on the network analysis and direct and indirect comparisons, the results of our retrospective clinical study indicated that i.v.-combined topical TXA was superior to the other eight variants with respect to low total blood loss and low risk of need for blood transfusion.

Initially, pairwise meta-analysis revealed that compared with the i.v. TXA, placebo + tourniquet, and i.v.combined topical TXA + tourniquet groups, the i.v.combined topical TXA group displayed less total blood loss and less reduction in hemoglobin value. Compared with the placebo and placebo + tourniquet, i.v. TXA groups, the topical TXA, the i.v.-combined topical TXA, i.v. TXA + tourniquet, topical TXA + tourniquet, and i.v.-combined topical TXA + tourniquet groups revealed 


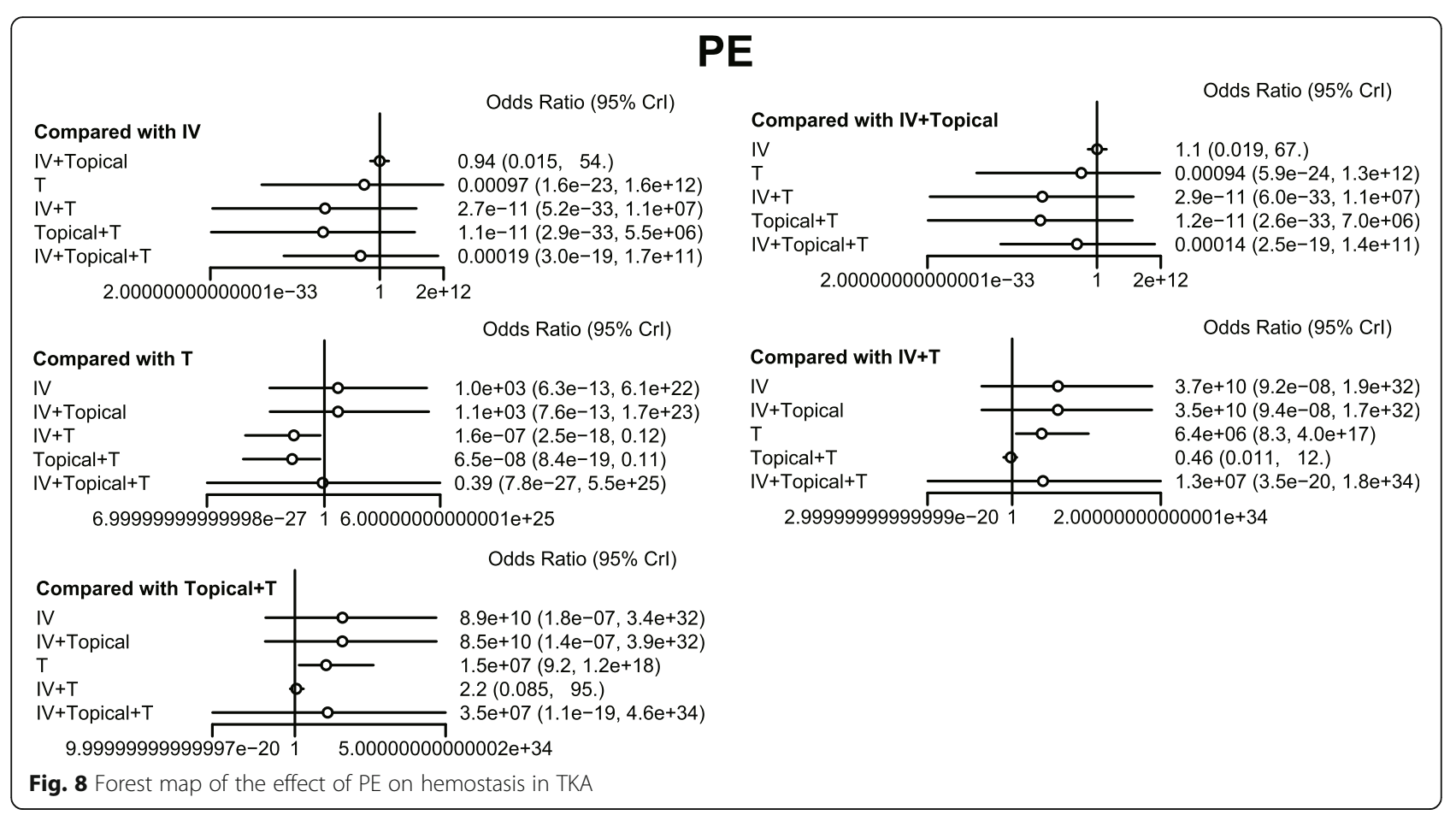

decreased blood transfusion risk and hemoglobin reduction value. Tourniquet application in TKA brings benefits of reduced intraoperative blood loss and operation time, but without significantly decreasing the need for blood transfusion or the rate of DVT in TKA [7]. However, using a tourniquet brings a certain risk of muscle damage, severe thigh pain, delayed rehabilitation, reduced patient satisfaction, and even paralysis due to nerve damage. Thus, some have speculated that TKA without tourniquet can avoid those adverse effects while promoting postoperative recovery [6]. Moreover, recent RCTs have proved that the routine use of TXA in TKA reduces blood loss and transfusion rates [36]. A prior study has evaluated the risks and benefits of tourniquet use compared with i.v. and topical administration of TXA in the setting of primary TKA, which revealed that i.v. and topical TXA without a tourniquet had less hidden blood loss, a lower incidence of postoperative knee swelling, less postoperative knee pain, lower levels of inflammatory biomarkers, and better early knee function along with greater ratings of patient satisfaction compared with those treated with a tourniquet [22]. Santias et al. have demonstrated that topical administration of TXA without tourniquet reduces blood loss and improves postoperative blood chemistries in patients receiving TKA without increasing the risk of thromboembolic complications [15]. In a study of 640 patients treated with either i.v. or topical TXA, greater blood loss was seen in the patients who received topical TXA, whereas i.v. administration achieved an immediate and desirable effect, especially in the absence of a tourniquet [13].

Additionally, NMA combined with the retrospective clinical study further validated that i.v.-combined topical TXA provides a low total blood loss without increasing blood transfusion risk. Additionally, this combined treatment had the lowest SUCRA values in terms of total blood loss (24.44\%) and blood transfusion risk (24.33\%), whereas topical TXA + tourniquet had the lowest SUCRA values in terms of hemoglobin reduction value $(37.46 \%)$, which also proved that i.v.combined topical TXA had the best hemostatic effects of tourniquet + TXA in TKA. Similarly, a recent study has displayed that, compared with either i.v. TXA or topical administration TXA alone, the combined administrated TXA can decrease the total blood loss, and the difference is statistically significant, whereas the pooled results indicated that combined topical with i.v. TXA decreased the need for transfusion [16]. Jain et al. have also concluded that combined i.v. with topical TXA provided better results than did i.v. alone with respect to mean calculated total blood loss, blood transfusion rate, hemoglobin drop, and the absence of significant effect on DVT [25]. These findings support that i.v.-combined topical TXA achieves better hemostatic effect following TKA. 


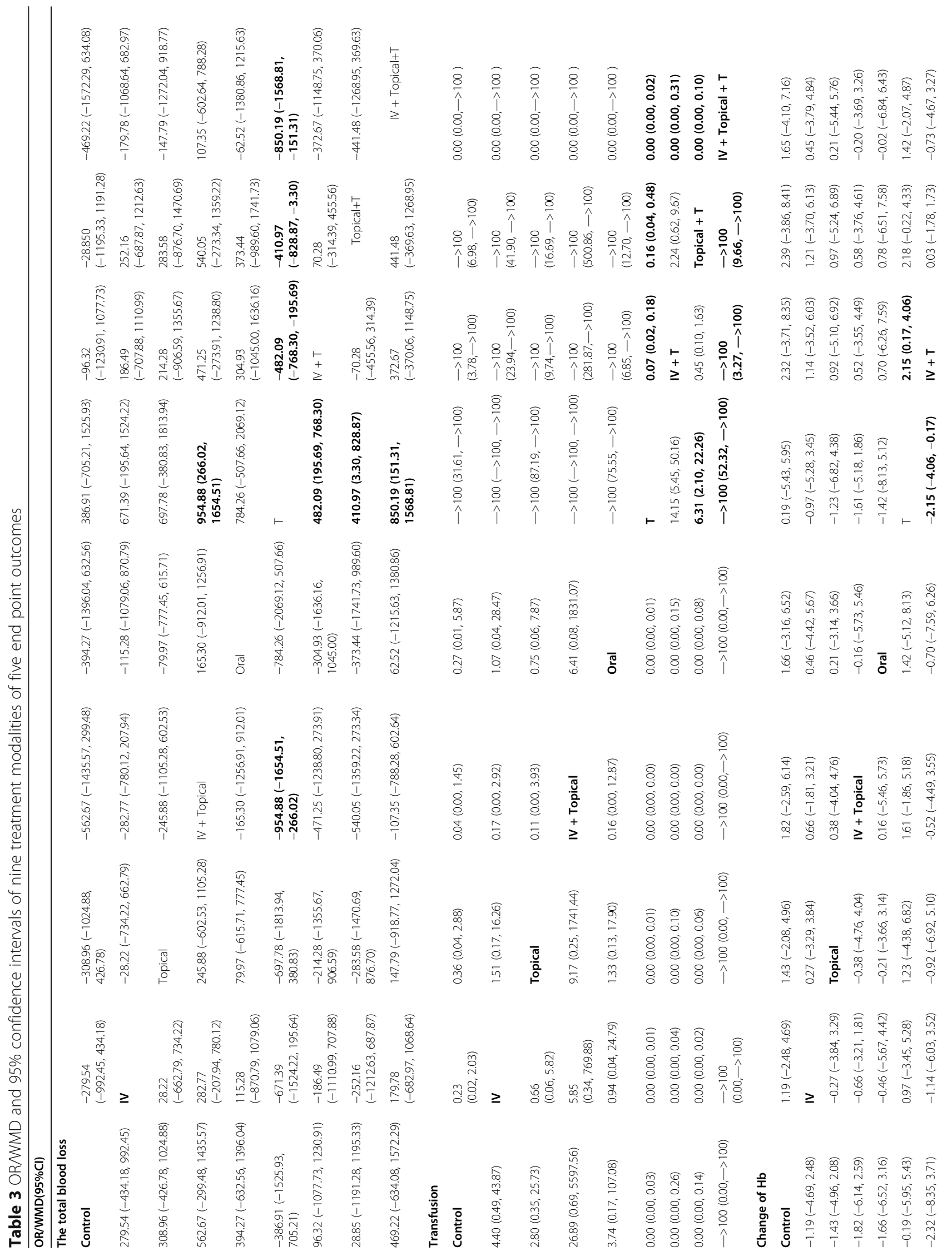




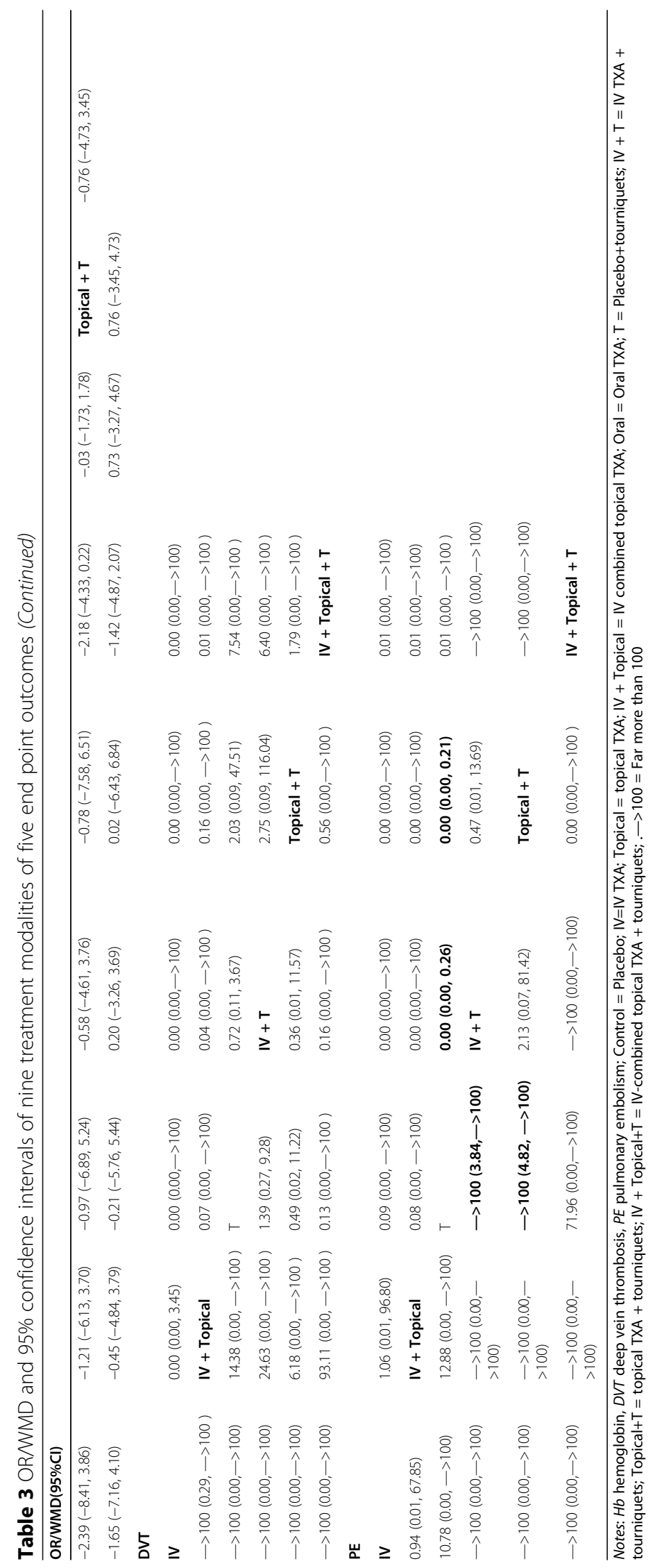


Table 4 Cumulative ranking probability of TKR main outcome indicators by different treatment measures (surface under the cumulative ranking curves, SUCRA)

\begin{tabular}{llll}
\hline & The total blood loss & Transfusion & Change of Hb \\
\hline Control & $2(87.67 \%)$ & $4(58.56 \%)$ & $2(79.84 \%)$ \\
IV TXA & $5(54.89 \%)$ & $7(38.22 \%)$ & $3(60.80 \%)$ \\
Topical TXA & $3(58.00 \%)$ & $5(43.44 \%)$ & $4(54.22 \%)$ \\
IV+topical TXA & $9(24.44 \%)$ & $9(24.33 \%)$ & $7(46.14 \%)$ \\
Oral TXA & $6(50.22 \%)$ & $6(38.67 \%)$ & $6(51.29 \%)$ \\
Placebo+tourniquet & $1(90.44 \%)$ & $1(100.00 \%)$ & $1(80.26 \%)$ \\
IV TXA+tourniquet & $7(49.44 \%)$ & $3(78.78 \%)$ & $8(37.87 \%)$ \\
Topical TXA+tourniquet & $4(56.33 \%)$ & $2(86.89 \%)$ & $9(37.46 \%)$ \\
IV+topical TXA+tourniquet & $8(29.22 \%)$ & $8(28.56 \%)$ & $5(52.13 \%)$ \\
\hline
\end{tabular}

$H b$ hemoglobin

However, there was a limitation in this study. The differences in the sample sizes of the nine variant interventions and the number of studies included in the direct matching comparison between various interventions have some impact on the research results. In this study, the hemostatic effect of TXA combined with a tourniquet on TKA was compared comprehensively from the perspectives of NMA and clinical research, which revealed important differences in the hemostatic outcomes of the nine variant intervention measures, notwithstanding statistical issues related to sample sizes in the literature.

\section{Conclusion}

In conclusion, i.v.-combined topical TXA contributes to lower total blood loss and blood transfusion risk in TKA patients. The i.v.-combined topical TXA proved to be superior to the other eight variant regiments, which calls for its adoption as standard care in TKA.

Table 5 Baseline characteristics and intraoperative and postoperative outcomes

\begin{tabular}{|c|c|c|c|c|c|c|c|c|c|}
\hline Group & IV TXA & TopicalTXA & $\begin{array}{l}\text { IV-combined } \\
\text { topical TXA }\end{array}$ & OralTXA & $\begin{array}{l}\text { Placebo }+ \\
\text { tourniquets }\end{array}$ & $\begin{array}{l}\text { IV TXA + } \\
\text { tourniquets }\end{array}$ & $\begin{array}{l}\text { Topical TXA + } \\
\text { tourniquets }\end{array}$ & $\begin{array}{l}\text { IV-combined } \\
\text { topical ITXA } \\
+ \text { tourniquets }\end{array}$ & $P$ value \\
\hline Number & 30 & 30 & 30 & 30 & 30 & 30 & 30 & 30 & \\
\hline Age(y) & $\begin{array}{l}67.77 \\
\pm 5.39\end{array}$ & $\begin{array}{l}67.37 \\
\pm 5.49\end{array}$ & $\begin{array}{l}66.73 \\
\pm 6.15\end{array}$ & $\begin{array}{l}66.3 \\
\pm 4.89\end{array}$ & $\begin{array}{l}65.23 \\
\pm 6.28\end{array}$ & $\begin{array}{l}65.73 \\
\pm 5.99\end{array}$ & $\begin{array}{l}67.13 \\
\pm 5.56\end{array}$ & $\begin{array}{l}65.43 \\
\pm 4.78\end{array}$ & 0.532 \\
\hline $\begin{array}{l}\text { Gender } \\
\text { (female/male) }\end{array}$ & $16 / 14$ & $20 / 10$ & $21 / 9$ & $15 / 15$ & $18 / 12$ & $16 / 14$ & $22 / 8$ & $21 / 9$ & 0.394 \\
\hline $\mathrm{BMI}(\mathrm{kg} / \mathrm{m} 2)$ & $\begin{array}{l}30.05 \\
\pm 3.02\end{array}$ & $\begin{array}{l}30.43 \\
\pm 4.28\end{array}$ & $\begin{array}{l}30.72 \\
\pm 2.93\end{array}$ & $\begin{array}{l}30.54 \\
\pm 3.09\end{array}$ & $\begin{array}{l}29.49 \\
\pm 3.87\end{array}$ & $\begin{array}{l}29.62 \\
\pm 3.37\end{array}$ & $\begin{array}{l}31.41 \\
\pm 3.62\end{array}$ & $\begin{array}{l}31.33 \\
\pm 4.11\end{array}$ & 0.307 \\
\hline Preop.ROM( $\left(^{\circ}\right)$ & $\begin{array}{l}99.87 \\
\pm 8.33\end{array}$ & $\begin{array}{l}100.01 \\
\pm 7.83\end{array}$ & $\begin{array}{r}103.45 \\
\pm 5.35\end{array}$ & $\begin{array}{l}101.53 \\
\pm 6.28\end{array}$ & $\begin{array}{l}102.08 \\
\pm 6.72\end{array}$ & $\begin{array}{l}99.37 \\
\pm 5.04\end{array}$ & $\begin{array}{l}100.88 \\
\pm 6.98\end{array}$ & $\begin{array}{r}102.41 \\
\pm 7.73\end{array}$ & 0.238 \\
\hline $\begin{array}{l}\text { Surgical } \\
\text { duration(min) }\end{array}$ & $\begin{array}{l}67.60 \\
\pm 12.39\end{array}$ & $\begin{array}{l}64.93 \\
\pm 10.79\end{array}$ & $\begin{array}{l}68.13 \\
\pm 8.97\end{array}$ & $\begin{array}{l}66.03 \\
\pm 12.17\end{array}$ & $\begin{array}{l}66.07 \\
\pm 9.75\end{array}$ & $\begin{array}{l}64.00 \\
\pm 8.53\end{array}$ & $\begin{array}{l}63.37 \\
\pm 12.18\end{array}$ & $\begin{array}{l}70.10 \\
\pm 11.18\end{array}$ & 0.256 \\
\hline Total blood loss(mL) & $\begin{array}{l}1268.84 \\
\pm 342.15\end{array}$ & $\begin{array}{l}1164.27 \\
\pm 304.19\end{array}$ & $\begin{array}{l}653.79 \\
\pm 246.20\end{array}$ & $\begin{array}{l}781.26 \\
\pm 213.79\end{array}$ & $\begin{array}{l}1584.33 \\
\pm 359.21\end{array}$ & $\begin{array}{l}1049.12 \\
\pm 266.72\end{array}$ & $\begin{array}{l}1002.48 \\
\pm 316.29\end{array}$ & $\begin{array}{l}739.15 \\
\pm 226.37\end{array}$ & $<0.001$ \\
\hline Transfusion & 9 & 5 & 1 & 7 & 12 & 3 & 5 & 4 & $0.009^{*}$ \\
\hline Preop.Hb(g/dL) & $\begin{array}{l}13.87 \\
\pm 0.66\end{array}$ & $\begin{array}{l}13.44 \\
\pm 1.23\end{array}$ & $\begin{array}{l}13.92 \\
\pm 1.25\end{array}$ & $\begin{array}{l}13.89 \\
\pm 0.95\end{array}$ & $\begin{array}{l}13.62 \\
\pm 1.02\end{array}$ & $\begin{array}{l}13.41 \\
\pm 1.07\end{array}$ & $\begin{array}{l}13.99 \\
\pm 1.09\end{array}$ & $\begin{array}{l}13.47 \\
\pm 0.72\end{array}$ & 0.117 \\
\hline 24-h Hb(g/dL) & $\begin{array}{l}11.82 \\
\pm 1.04\end{array}$ & $\begin{array}{l}11.49 \\
\pm 1.30\end{array}$ & $\begin{array}{l}12.09 \\
\pm 1.40\end{array}$ & $\begin{array}{l}12.74 \\
\pm 0.94\end{array}$ & $\begin{array}{l}10.37 \\
\pm 1.26\end{array}$ & $\begin{array}{l}11.48 \\
\pm 1.35\end{array}$ & $\begin{array}{l}11.94 \\
\pm 1.31\end{array}$ & $\begin{array}{l}12.11 \\
\pm 0.95\end{array}$ & $<0.001^{*}$ \\
\hline $\begin{array}{l}\text { Hb change } \\
(\mathrm{g} / \mathrm{dL})\end{array}$ & $\begin{array}{l}2.02 \\
\pm 0.84\end{array}$ & $\begin{array}{l}1.95 \\
\pm 0.57\end{array}$ & $\begin{array}{l}1.83 \\
\pm 0.61\end{array}$ & $\begin{array}{l}1.14 \\
\pm 0.39\end{array}$ & $\begin{array}{l}3.22 \\
\pm 1.06\end{array}$ & $\begin{array}{l}1.93 \\
\pm 0.75\end{array}$ & $\begin{array}{l}2.09 \\
\pm 0.61\end{array}$ & $\begin{array}{l}1.36 \\
\pm 0.55\end{array}$ & $<0.001^{*}$ \\
\hline DVT & 1 & 0 & 0 & 0 & 0 & 1 & 0 & 0 & 0.541 \\
\hline PE & 0 & 0 & 0 & 0 & 0 & 0 & 1 & 0 & 0.432 \\
\hline
\end{tabular}

Notes: Preop.ROM preoperative range of motion, Preop. $\mathrm{Hb}$ preoperative hemoglobin. Measurement data are presented as mean \pm standard deviation. Comparisons among multiple groups were analyzed using ANOVA, followed by Tukey's post hoc test. Enumeration data were analyzed by chi-square test. ${ }^{*} p<0.05$ 


\section{Supplementary information}

Supplementary information accompanies this paper at https://doi.org/10. 1186/s13018-020-02010-z.

Additional file 1: Fig. S1. Flow chart of literature screening

\section{Abbreviations}

TKA: Total knee arthroplasty; TXA: Tranexamic acid; RCTs: Randomized controlled trials; DVT: Deep vein thrombosis; i.v.: Intravenous; PE: Pulmonary embolism; Cl: Confidence interval; SUCRA: Surface under the cumulative ranking curve; IA: Intra-articular

\section{Acknowledgements}

We would like to show sincere appreciation to the reviewers for critical comments on this article.

\section{Authors' contributions}

YZ and GZ designed the study. YZ and FW collated the data, carried out data analyses, and produced the initial draft of the manuscript. $B L$ and $G Z$ contributed to drafting the manuscript. All authors have read and approved the final submitted manuscript.

\section{Funding}

This study was funded by the Natural Science Foundation of Shandong Province (Project No. ZR2019PH026), Subject name: the mechanism and clinical application of miR-34a chondrocyte aging mediated by sestrin2 /mTORC1 in developmental dysplasia of the hip joint. Weifang Health Committee (Project No.2017WSJS002), Prevention of deep venous thrombosis in the lower extremity during the perioperative period of joint surgery by tertiary prevention combined with cocktail monitoring.

\section{Availability of data and materials}

The datasets generated/analyzed during the current study are available.

\section{Ethics approval and consent to participate}

This article does not contain any studies with human participants or animals performed by any of the authors.

\section{Consent for publication}

Consent for publication was obtained from the participants.

\section{Competing interests}

The authors confirm that there are no conflicts of interest.

\section{Author details}

'Joint Surgery Department, Weifang People's Hospital, Weifang 261000, People's Republic of China. ${ }^{2}$ Anesthesiology Department, Weifang People's Hospital, Weifang 261000, People's Republic of China. ${ }^{3}$ Medical Department, Weifang People's Hospital, No. 151, Guangwen Road, Kuiwen District, Weifang 261000, Shandong Province, People's Republic of China. ${ }^{4}$ Orthopaedics Department, People's Hospital of Xiashan Ecological and Economic Development Zone, No. 1, Xiashou Road, Xiashan District, Weifang 261325, Shandong Province, People's Republic of China.

Received: 6 May 2020 Accepted: 6 October 2020

Published online: 12 November 2020

\section{References}

1. Kim JL, Park JH, Han SB, Cho IY, Jang KM. Allogeneic blood transfusion is a significant risk factor for surgical-site infection following total hip and knee arthroplasty: a meta-analysis. J Arthroplast. 2017;32:320-5.

2. Rosenstein AD, Michelov YA, Thompson S, Kaye AD. Benefits of limited use of a tourniquet combined with intravenous tranexamic acid during total knee arthroplasty. Ochsner J. 2016;16:443-9.

3. George J, Eachempati KK, Subramanyam KN, Gurava Reddy AV. The comparative efficacy and safety of topical and intravenous tranexamic acid for reducing perioperative blood loss in total knee arthroplasty-a randomized controlled non-inferiority trial. Knee. 2018;25:185-91.
4. Levine BR, Haughom B, Strong B, Hellman M, Frank RM. Blood management strategies for total knee arthroplasty. J Am Acad Orthop Surg. 2014;22:361-71.

5. Wang D, Zhu H, Meng WK, Wang HY, Luo ZY, Pei FX, et al. Comparison of oral versus intra-articular tranexamic acid in enhanced-recovery primary total knee arthroplasty without tourniquet application: a randomized controlled trial. BMC Musculoskelet Disord. 2018;19:85.

6. Wang HY, Wang L, Luo ZY, Wang D, Tang $X$, Zhou ZK, et al. Intravenous and subsequent long-term oral tranexamic acid in enhanced-recovery primary total knee arthroplasty without the application of a tourniquet: a randomized placebo-controlled trial. BMC Musculoskelet Disord. 2019;20:478

7. Cai DF, Fan $\mathrm{QH}$, Zhong $\mathrm{HH}$, Peng $\mathrm{S}$, Song $\mathrm{H}$. The effects of tourniquet use on blood loss in primary total knee arthroplasty for patients with osteoarthritis: a meta-analysis. J Orthop Surg Res. 2019;14:348

8. Dennis DA, Kittelson AJ, Yang CC, Miner TM, Kim RH, Stevens-Lapsley JE. Does tourniquet use in TKA affect recovery of lower extremity strength and function? A randomized trial. Clin Orthop Relat Res. 2016;474:69-77.

9. Ajnin S, Fernandes R. Reduced length of stay and faster recovery after total knee arthroplasty without the use of tourniquet. J Clin Orthop Trauma. 2020;11:129-32.

10. Stetzelberger $V$, Obertacke $U$, Jawhar A. Tourniquet application during TKA did not affect the accuracy of implant positioning: a randomized clinical trial. Knee Surg Sports Traumatol Arthrosc. 2018;26:1728-36.

11. Ayik O, Demirel M, Birisik F, Ersen A, Balci Hl, Sahinkaya T, et al. The Effects of tourniquet application in total knee arthroplasty on the recovery of thigh muscle strength and clinical outcomes. J Knee Surg. 2020. Online ahead of print

12. Wu KT, Siu KK, Ko JY, Chou WY, Kuo SJ, Hsu YH. Tranexamic acid reduces total blood loss and inflammatory response in computer-assisted navigation total knee arthroplasty. Biomed Res Int. 2019;2019:5207517.

13. Jules-Elysee KM, Tseng A, Sculco TP, Baaklini LR, McLawhorn AS, Pickard AJ, et al. Comparison of topical and intravenous tranexamic acid for total knee replacement: a randomized double-blinded controlled study of effects on tranexamic acid levels and thrombogenic and inflammatory marker levels. J Bone Joint Surg Am. 2019

14. Aytuluk HG, Yaka HO. Tranexamic acid is effective in lower doses with infusion in total knee arthroplasty. Acta Orthop Traumatol Turc. 2019:53:81-5.

15. Morales Santias M, Mas Martinez J, Sanz-Reig J, Martinez Gimenez E, Verdu Roman C, Bustamante Suarez de Puga D. Topical tranexamic acid in cemented primary total knee arthroplasty without tourniquet: a prospective randomized study. Eur J Orthop Surg Traumatol. 2020;30:1003-8.

16. Lin C, Qi Y, Jie L, Li HB, Zhao XC, Qin L, et al. Is combined topical with intravenous tranexamic acid superior than topical, intravenous tranexamic acid alone and control groups for blood loss controlling after total knee arthroplasty: A meta-analysis. Medicine (Baltimore). 2016;95:e5344.

17. Higgins JP, Altman DG, Gotzsche PC, Juni P, Moher D, Oxman AD, et al. The Cochrane Collaboration's tool for assessing risk of bias in randomised trials. BMJ. 2011:343:d5928

18. Chung JH, Lee SW. Assessing the quality of randomized controlled urological trials conducted by Korean Medical Institutions. Korean J Urol. 2013;54:289-96

19. Zhu GQ, Shi KQ, Huang S, Wang LR, Lin YQ, Huang GQ et al. Systematic review with network meta-analysis: the comparative effectiveness and safety of interventions in patients with overt hepatic encephalopathy. Aliment Pharmacol Ther. 2015;41:624-35.

20. Chaimani A, Higgins JP, Mavridis D, Spyridonos P, Salanti G. Graphical tools for network meta-analysis in STATA. PLoS One. 2013;8:e76654

21. Salanti G, Ades AE, loannidis JP. Graphical methods and numerical summaries for presenting results from multiple-treatment meta-analysis: an overview and tutorial. J Clin Epidemiol. 2011;64:163-71.

22. Huang Z, Xie X, Li L, Huang Q, Ma J, Shen B, et al. Intravenous and topical tranexamic acid alone are superior to tourniquet use for primary total knee arthroplasty: a prospective, randomized controlled trial. J Bone Joint Surg Am. 2017;99:2053-61.

23. Tzatzairis TK, Drosos GI, Kotsios SE, Ververidis AN, Vogiatzaki TD, Kazakos KI. Intravenous vs topical tranexamic acid in total knee arthroplasty without tourniquet application: a randomized controlled study. J Arthroplast. 2016; 31:2465-70

24. Nielsen CS, Jans O, Orsnes T, Foss NB, Troelsen A, Husted H. Combined intra-articular and intravenous tranexamic acid reduces blood loss in total 
knee arthroplasty: a randomized, double-blind, placebo-controlled trial. J Bone Joint Surg Am. 2016;98:835-41.

25. Jain NP, Nisthane PP, Shah NA. Combined Administration of systemic and topical tranexamic acid for total knee arthroplasty: can it be a better regimen and yet safe? A randomized controlled trial. J Arthroplast. 2016;31: $542-7$.

26. May JH, Rieser GR, Williams CG, Markert RJ, Bauman RD, Lawless MW. The Assessment of blood loss during total knee arthroplasty when comparing intravenous vs intracapsular administration of tranexamic acid. J Arthroplast. 2016;31:2452-7.

27. Drosos Gl, Ververidis A, Valkanis C, Tripsianis G, Stavroulakis E, Vogiatzaki T, et al. A randomized comparative study of topical versus intravenous tranexamic acid administration in enhanced recovery after surgery (ERAS) total knee replacement. J Orthop. 2016;13:127-31.

28. Yang Y, LV YM, Ding PJ, Li J, Ying-Ze Z. The reduction in blood loss with intra-articular injection of tranexamic acid in unilateral total knee arthroplasty without operative drains: a randomized controlled trial. Eur J Orthop Surg Traumatol. 2015;25:135-9.

29. Robinson MH. The role of biological research in the development of facilities. J Anim Sci. 1989;67:2441-51.

30. Patel JN, Spanyer JM, Smith LS, Huang J, Yakkanti MR, Malkani AL. Comparison of intravenous versus topical tranexamic acid in total knee arthroplasty: a prospective randomized study. J Arthroplast. 2014;29: 1528-31.

31. Good L, Peterson E, Lisander B. Tranexamic acid decreases external blood loss but not hidden blood loss in total knee replacement. Br J Anaesth. 2003;90:596-9

32. Tanaka N, Sakahashi H, Sato E, Hirose K, Ishima T, Ishii S. Timing of the administration of tranexamic acid for maximum reduction in blood loss in arthroplasty of the knee. J Bone Joint Surg (Br). 2001;83:702-5.

33. Jansen AJ, Andreica S, Claeys M, D'Haese J, Camu F, Jochmans K. Use of tranexamic acid for an effective blood conservation strategy after total knee arthroplasty. Br J Anaesth. 1999;83:596-601.

34. Benoni $\mathrm{G}$, Fredin $\mathrm{H}$. Fibrinolytic inhibition with tranexamic acid reduces blood loss and blood transfusion after knee arthroplasty: a prospective, randomised, double-blind study of 86 patients. J Bone Joint Surg (Br). 1996; 78:434-40.

35. Yuan ZF, Yin H, Ma WP, Xing DL. The combined effect of administration of intravenous and topical tranexamic acid on blood loss and transfusion rate in total knee arthroplasty: Combined tranexamic acid for TKA. Bone Joint Res. 2016;5:353-61.

36. Cankaya D, Dasar U, Satilmis AB, Basaran SH, Akkaya M, Bozkurt M. The combined use of oral and topical tranexamic acid is a safe, efficient and low-cost method in reducing blood loss and transfusion rates in total knee arthroplasty. J Orthop Surg (Hong Kong). 2017;25:2309499016684725.

\section{Publisher's Note}

Springer Nature remains neutral with regard to jurisdictional claims in published maps and institutional affiliations.

Ready to submit your research? Choose BMC and benefit from:

- fast, convenient online submission

- thorough peer review by experienced researchers in your field

- rapid publication on acceptance

- support for research data, including large and complex data types

- gold Open Access which fosters wider collaboration and increased citations

- maximum visibility for your research: over $100 \mathrm{M}$ website views per year

At $\mathrm{BMC}$, research is always in progress.

Learn more biomedcentral.com/submissions 